\title{
Determination of Clocapramine and Its Metabolites in Plasma by Automated Column-Switching High Performance Liquid Chromatography
}

\author{
Kozo Hikida*, Yoshimasa INOUE*, Norio KoJIMA* and Yosuke OHKURA** \\ *Department of Quality Control, Yoshitomi Pharmaceutical Industries Ltd., \\ Yoshitomi, Fukuoka 871, Japan \\ **Faculty of Pharmaceutical Sciences, Kyushu University 62, Maidashi, Fukuoka 812, Japan
}

\begin{abstract}
An automated column-switching high performance liquid chromatographic method with ultraviolet detection is described for rapid and sensitive determination of clocapramine, a psychotropic drug, and its two metabolites, clospipramine and dehydroclospipramine, in dog and human plasmas. The drug and the metabolites were extracted together with trifluperidol as an internal standard with a heptane-chloroform mixture from plasma. The extract was subjected to column-switching high performance liquid chromatography using a bovine serum albumin-coated cyanopropyl silica gel column, a newly developed sample clean-up column, and a reversed phase column (TSK gel ODS-80TM) for analytical separation. The detection limits $(S / N=3)$ of clocapramine, clospipramine and dehydroclospipramine were $0.5-1.0 \mathrm{ng} \mathrm{ml}^{-1}$.
\end{abstract}

Keywords Column-switching high performance liquid chromatography, clocapramine, metabolite, clospipramine, dehydroclospipramine, plasma, bovine serum albumin-coated cyanopropyl silica gel column

Clocapramine, dihydrochloride of 3-chloro-5-[3-(4carbamoyl-4-piperidinopiperidino)propyl]-10,11-dihydro-5 $H$-dibenzo $[b, f]$ azepine (CCP; Fig. 1$)$ is currently used as a psychotropic drug. The pharmacokinetics and biotransformation of CCP in dogs and humans have recently been described; 1 CCP dosed orally is metabolized to clospipramine, ( \pm )-3-chloro-5-[3-(2oxo-1,2,3,5,6,7,8,8a-octahydroimidazo[1,2-a]pyridine-3spiro-4-piperidino)propyl]-10,11-dihydro-5 $\mathrm{H}$-dibenzo$[b, f]$ azepine (CSP; Fig. 1$)$ in man and to both CSP and dehydroclospipramine, 1,8a-di(dehydro)-derivative of CSP (DCSP; Fig. 1) in dogs. Recently, we have found that DCSP also occurs in human plasma when CCP is continuously administered in a therapeutic dose range (unpubished data).

High performance liquid chromatographic (HPLC) methods have been reported for the determination of $\mathrm{CCP}^{2}$ and of CCP, CSP and DCSP ${ }^{1}$ in plasma. These methods require complex extraction steps in the sample clean-up procedures that are time-consuming and cause unsatisfactory recoveries of the metabolites.

For monitoring the concentration of $\mathrm{CCP}$ and the metabolites in plasma from patients dosed with CCP and for investigating the bioequivalency of CCP preparations, a sensitive and selective method is still required. Automated column-switching HPLC technique has been used for determination of compounds in complex samples 3,4 , and we have applied this technique with ultraviolet (UV) detection to the determination of drugs (ampicillin ${ }^{5}$, cephalexin ${ }^{6}$, bromperidol ${ }^{7}$ and pranoprofen ${ }^{8}$ ) in serum or plasma. This study was designed to establish a method for simultaneous determination of CCP, CSP and DCSP in dog and human plasmas. This method is based on the above-mentioned HPLC technique with UV detection using a newly developed bovine serum albumin-coated cyanopropyl silica gel column for sample clean-up and a reversed-phase

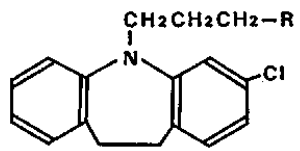<smiles>NC(=O)C1(CN2CCCCC2)CCN([18O])CC1</smiles><smiles>O=C(O)C1(C(=O)N=C2CCCCN2C2CCCCC2)CCN(P)CC1</smiles>

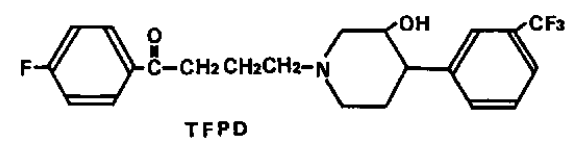

Fig. 1 Structures of CCP, CSP, DCSP and TFPD. 
column for analytical separation. Hydrochloride of trifluperidol, 4-[4-( $m$-trifluoromethylphenyl)-4-hydroxypiperidino]-4'-fluorobutyrophenone (TFPD; Fig. 1) was used as an internal standard. Plasma levels of CCP, CSP and DCSP after oral administration of CCP were determined by using the method developed.

\section{Experimental}

\section{Materials and solutions}

CCP dihydrochloride and its tablets were the products of Yoshitomi Pharmaceutical Industries Ltd. (Osaka, Japan). CSP and DCSP were synthesized in the Research Laboratories of Yoshitomi Pharmaceutical Industries Ltd. TFPD hydrochloride was the product of Janssen Pharmaceutica (Beerse, Belgium). Deionized water was passed through a Milli-Q system (Millipore, Bedford, MA, USA) just before use. Other chemicals were of reagent grade. CCP, CSP and DCSP standard solutions $\left(10-100 \mathrm{ng} \mathrm{ml}^{-1}\right.$ each) were prepared by dissolving each compound in a small amount of $0.1 \mathrm{M} \mathrm{HCl}$ and diluting with eluent $\mathrm{A}$ (see below). TFPD hydrochloride solution $\left(75 \mathrm{ng} \mathrm{ml}^{-1}\right.$; internal standard solution) was prepared in the same manner. Plasma was obtained from dogs (male beagle, 1 year old, $10.5-11.5 \mathrm{~kg}$ weight) and schizophrenic patients (27-42 years old) in the usual manner.

\section{Apparatus}

A column-switching HPLC system (Fig. 2) consisted of a Shimadzu LC-5A high pressure pump (for a mobile phase (eluent $A$ ) of acetonitrile and $0.1 \mathrm{M}$ $\mathrm{KH}_{2} \mathrm{PO}_{4}$ (pH 2.2, adjusted with $\left.6 \mathrm{M} \mathrm{HClO}_{4}\right)(1: 9, \mathrm{v} / \mathrm{v})$ ), a Shimadzu LC-3A high pressure pump (for another mobile phase (eluent B) of acetonitrile and $0.1 \mathrm{M}$ $\left.\mathrm{KH}_{2} \mathrm{PO}_{4}(\mathrm{pH}=2.2)(47: 53, \mathrm{v} / \mathrm{v})\right)$, a Tosoh PT-8000 multiple autovalve, an Atto SJ-1700AS autosampler (500- $\mu$ injection volume), a Shimadzu Chromatopac C-

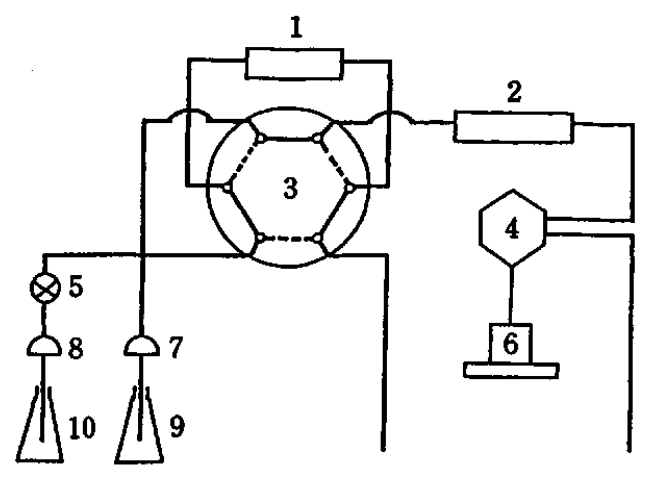

Fig. 2 Flow diagram of HPLC system with automated sample preparation. 1, column I; 2, column II; 3, column switching valve; 4 , UV detector; 5 , autosampler; 6 , data processor; 7, pump for analytical separation; 8 , pump for sample clean-up; 9, eluent B; 10, eluent A.
R2A data processor and a Shimadzu SPD-2A UV monitor fitted with 8- $\mu 1$ cell. A column of a cyanopropyl silica gel (end-capped with trimethylsilyl chloride; carbon content, 5.5\%) coated with bovine serum albumin (column I; $35 \times 4.6 \mathrm{~mm}$ i.d.; particle size $5 \mu \mathrm{m})$ was developed for this study. It was donated from Tosoh Corporation, Tokyo, Japan and it was used for sample clean-up. A reversed-phase column, TSK gel ODS-80TM (column II; $150 \times 4.6 \mathrm{~mm}$ i.d.; particle size $5 \mu \mathrm{m}$; Tosoh), was used as an analytical column.

\section{Extraction procedure}

To plasma $(2.0 \mathrm{ml})$ were added $1.0 \mathrm{ml}$ each of the internal standard solution and $2.5 \mathrm{M} \mathrm{NaOH}$ and $15 \mathrm{ml}$ of a mixture of heptane-chloroform $(7: 3, v / v)$, and the mixture was shaken vigorously for $15 \mathrm{~min}$. Then, the mixture was centrifuged at $2000 \mathrm{~g}$ for $10 \mathrm{~min}$. A $10 \mathrm{ml}$ portion of the organic layer was evaporated in vacuo at $45^{\circ} \mathrm{C}$ to dryness. The residue was dissolved in $0.75 \mathrm{ml}$ of eluent $A$ and used as an extract sample.

\section{HPLC system and its operation}

A $0.5 \mathrm{ml}$ portion of the extract sample was automatically injected into the HPLC system. The system was operated according to the time program depicted in Table 1. Between 0-10.5 min after the sample injection, CCP, CSP, DCSP and TFPD were separated from the interfering substances present in the extract on column I with eluent A. Between 10.5-12.3 min after the injection, these compounds retained on column I were eluted out with eluent $B$ and the effluent from column I was switched to column II. Then CCP, CSP, DCSP and TFPD were separated on column II by eluting with eluent $B$ (between $12.3-35.0 \mathrm{~min}$ ). The flow rates of eluents $A$ and $B$ were 1.2 and $0.6 \mathrm{ml} \mathrm{min}^{-1}$, respectively. The column temperature was ambient $\left(22-26^{\circ} \mathrm{C}\right)$. The absorbance of the effluent from column II was monitored at $253 \mathrm{~nm}$ with a sensitivity of 0.005 absorbance units full scale. The peak height was used for quantification.

\section{Results and Discussion}

\section{Extraction}

CCP, CSP, DCSP and TFPD in plasma were extracted with organic solvents after the plasma was diluted with sodium hydroxide solution. Virtually

Table 1 Time program

\begin{tabular}{rcc}
\hline \multirow{2}{*}{ Time/min } & \multicolumn{2}{c}{ Eluent } \\
\cline { 2 - 3 } & Column I & Column II \\
\hline $0-10.5$ & A & B \\
$10.5-12.3$ & B & B \\
$12.3-35.0$ & A & B \\
\hline
\end{tabular}


Table 2 Recoveries of CCP, CSP, DCSP and TFPD spiked into different drug-free human plasma samples ${ }^{2}$

\begin{tabular}{cccc}
\hline Compound & $\begin{array}{c}\text { Added/ } \\
\text { ng ml }^{-1}\end{array}$ & $\begin{array}{c}\text { Recovery, } \\
\%\end{array}$ & $\begin{array}{c}\text { RSD, } \\
\%\end{array}$ \\
\hline CCP & 20.0 & 97.8 & 1.2 \\
& 40.0 & 97.2 & 2.7 \\
& 80.0 & 96.7 & 2.7 \\
CSP & 20.0 & 90.1 & 3.9 \\
& 40.0 & 90.0 & 2.8 \\
DCSP & 80.0 & 90.1 & 1.0 \\
& 20.0 & 93.7 & 3.1 \\
& 40.0 & 96.6 & 2.0 \\
TFPD & 80.0 & 97.3 & 1.7 \\
\hline
\end{tabular}

a. $n=7$ in each case.

complete recoveries were attained by using a heptanechloroform mixture $(7: 3, v / v)($ Table 2$)$. The extract was dissolved in eluent $\mathrm{A}\left(0.1 \mathrm{M} \mathrm{KH}_{2} \mathrm{PO}_{4}(\mathrm{pH}=2.2)\right.$ containing $10 \%$ acetonitrile) and subjected to the column-switching HPLC. If the extract was dissolved in the phosphate solution containing acetonitrile at a concentration of $40 \%$ or more, the peaks in the chromatogram for the four compounds badly broadened.

\section{Column-switching HPLC}

A bovine serum albumin-coated ODS column ${ }^{9}$ such as TSK precolumn BSA-ODS column $(35 \times 4.6 \mathrm{~mm}$ i.d., particle size $10 \mu \mathrm{m}$; Tosoh) has often been used for sample clean-up in the determination of moderately hydrophobic analytes in plasma or serum. However, CCP, CSP, DCSP and TFPD were all fairly hydrophobic in eluent $A$ and so they were strongly retained on such a column. Furthermore, these compounds could not be successfully fractionated from interfering substances present in the extract. In contrast, a good separation of the compounds from the interfering substances was achieved by using a bovine serum albumin-coated cyanopropyl silica gel column (column I), which has a moderate affinity for CCP, CSP, DCSP and TFPD in eluent $A$.

Eluent $A$ provided the best efficiency as a mobile phase for the clean-up: acetonitrile acted to separate the analytes from other components of the extract, and pH 2.2 gave a sufficient affinity of the analytes to column I.

CCP, CSP, DCSP and TFPD retained on column I should be transferred and separated on column II, a TSK gel ODS-80TM column. The transference was attained by using the phosphate solution mixed with acetonitrile $(53: 47, \mathrm{v} / \mathrm{v})$ (eluent $B)$ which has a stronger elution power than eluent $A$. Eluent $B$ could also afford a good resolution of the four compounds. Other reversed-phase columns (YMC-C8 (150)4.6 mm i.d.; particle size $5 \mu \mathrm{m}$; Yamamura Chemical Laboratories,

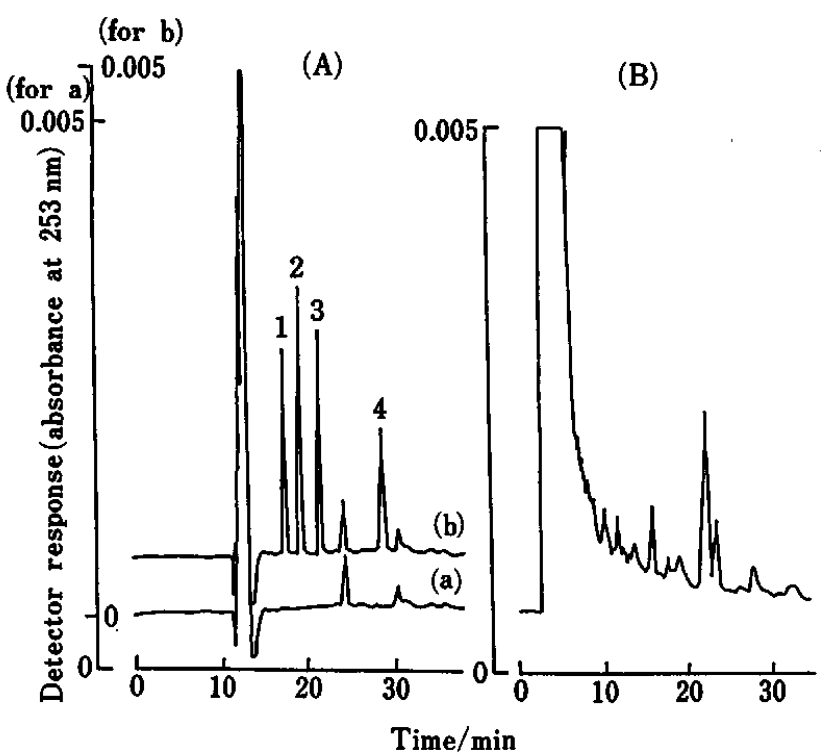

Fig. 3 Chromatograms of (A) extracts of (a) a drug-free human plasma and (b) the plasma spiked with $\mathrm{CCP}$ dihydrochloride $\left(30 \mathrm{ng} \mathrm{ml}^{-1}\right)$, CSP $\left(40 \mathrm{ng} \mathrm{m}^{-1}\right)$, DCSP (35 $\mathrm{ng} \mathrm{m}^{-1}$ ) and TFPD hydrochloride (37.5 $\mathrm{ng} \mathrm{ml}^{-1}$ ), and (B) an extract of the drug-free human plasma that was injected directly onto column II. Peaks: 1, CCP; 2, DCSP; 3, TFPD; 4, CSP.

Kyoto, Japan) and PCI-101 (150×4.6 mm i.d.; particle size $5 \mu \mathrm{m}$; Toa Electronics Ltd., Tokyo, Japan)) showed a poor resolution of DCSP and TFPD.

Figure 3(A) shows typical chromatograms of the extracts of a drug-free human plasma (a) and of the plasma spiked with CCP, DCSP, TFPD and CSP (b) (retention times: 18.5, 19.9, 22.0 and $28.6 \mathrm{~min}$, respectively). No interfering peaks were observed in the chromatograms. When an extract of the drug-free plasma was separated only on column II without using the column-switching technique, many peaks were observed on the chromatogram (Fig. 3(B)), these peaks interfered with the detection of the peaks for the four compounds.

\section{Validation of the method}

The calibration graphs for CCP, CSP and DCSP in the internal standard method were linear up to at least $100 \mathrm{ng} \mathrm{ml}^{-1}$. The regression equations (the peak-height ratio $(y)$ and the drug or metabolite concentration $(x$, $\mathrm{ng} \mathrm{ml} \mathrm{m}^{-1}$ ) added in the range 20-200 $\mathrm{ng}$ to $2 \mathrm{ml}$ of a drug-free plasma). The regression coefficients $(r)$ are:

$$
\begin{aligned}
& y=0.0124 x-0.0325 \text { and } r=0.998 \text { for CCP, } \\
& y=0.0096 x-0.0110 \text { and } r=0.996 \text { for CSP }
\end{aligned}
$$

and

$$
y=0.0170 x-0.0457 \text { and } r=0.998 \text { for DCSP. }
$$

The detection limits were $0.5 \mathrm{ng} \mathrm{ml}^{-1}$ for both CCP and DCSP and $1.0 \mathrm{ng} \mathrm{ml}^{-1}$ for CSP at a signal-to-noise ratio of 3. The within-day $(n=6)$ and between-day 
Table 3 Precision data for CCP and its metabolites in dog plasma

\begin{tabular}{lccccc}
\hline \multirow{2}{*}{ Compound } & \multicolumn{2}{c}{$\begin{array}{c}\text { Within-day } \\
\text { precision }\end{array}$} & & \multicolumn{2}{c}{$\begin{array}{c}\text { Between-day } \\
\text { precision }\end{array}$} \\
\cline { 2 - 3 } \cline { 5 - 6 } & $\begin{array}{c}\text { Concentration } \\
\text { ng ml }^{-1}\end{array}$ & $\begin{array}{c}\text { RSD, } \\
\%\end{array}$ & $\begin{array}{c}\text { Concentration } \\
\text { ng ml }^{-1}\end{array}$ & $\begin{array}{c}\text { RSD, } \\
\%\end{array}$ \\
\hline CCP & $13.7 \pm 0.4$ & 3.0 & $13.6 \pm 0.4$ & 3.1 \\
& $26.8 \pm 0.7$ & 2.7 & $27.5 \pm 0.8$ & 3.0 \\
CSP & $53.7 \pm 0.9$ & 1.6 & $53.9 \pm 1.3$ & 2.5 \\
& $14.6 \pm 0.4$ & 3.0 & $15.2 \pm 0.5$ & 3.5 \\
& $28.6 \pm 0.7$ & 2.2 & $29.4 \pm 0.9$ & 3.0 \\
DCSP & $57.9 \pm 0.9$ & 1.6 & $58.1 \pm 1.5$ & 2.5 \\
& $15.7 \pm 0.5$ & 3.0 & $15.6 \pm 0.5$ & 3.4 \\
& $32.1 \pm 0.5$ & 1.6 & $33.1 \pm 1.0$ & 3.0 \\
& $65.0 \pm 1.1$ & 1.7 & $66.4 \pm 1.6$ & 2.4 \\
\hline
\end{tabular}

a. Mean \pm standard deviation, $n=6$.

b. Mean \pm standard deviation, $n=36$.

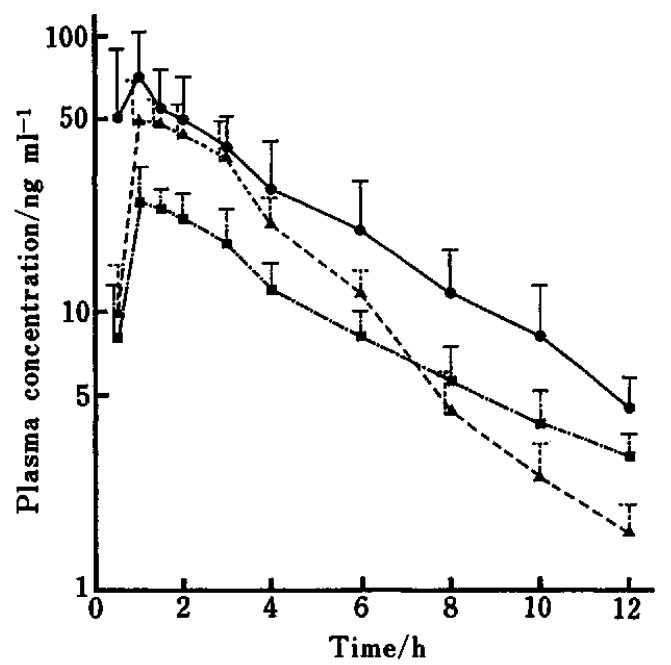

Fig. 4 Time-concentration curves for CCP (- - ), CSP (-.-.-1.--) and DCSP (--after single oral administration of one tablet of CCP dihydrochloride $(50 \mathrm{mg}$ ). Each plot and vertical line represent the mean $(n=4)$ and standard deviation, respectively.

(duplicate determinations a day for 18 days; total $n=36$ ) precisions were established (Table 3). The relative standard deviations did not exceed $3.0 \%$ in the withinday assay and $3.5 \%$ in the between-day assay.

\section{Concentrations of CCP and its metabolites in dog and human plasmas}

Figure 4 shows time-concentration curves obtained with dog plasma after single oral administration of a tablet of CCP dihydrochloride $(50 \mathrm{mg})$. The concentrations of CCP and its metabolites in plasma were fit to the one-compartment open model of drug disposition. $\mathrm{CCP}$ was rapidly absorbed, reached a maximum value of $71.4 \mathrm{ng} \mathrm{ml}^{-1}$ at $1.0 \mathrm{~h}$, and was eliminated with a half-
Table 4 Concentrations of CCP and its metabolites in plasma of patients receiving oral administration of $\mathrm{CCP}^{\mathrm{a}}$

\begin{tabular}{|c|c|c|c|c|c|}
\hline \multirow{2}{*}{ Patient $^{\mathrm{b}}$} & \multirow{2}{*}{$\begin{array}{c}\text { Therapy } \\
\text { duration/ } \\
\text { month }\end{array}$} & \multirow{2}{*}{$\begin{array}{l}\text { Dose/ } \\
\mathrm{mg} \mathrm{d}^{-1}\end{array}$} & \multicolumn{3}{|c|}{ Concentration $/ \mathrm{ng} \mathrm{ml}^{-1}$} \\
\hline & & & $\mathrm{CCP}$ & CSP & DCSP \\
\hline $\mathbf{A}$ & 14 & 50 & 48.7 & 4.9 & 17.4 \\
\hline B & 32 & 100 & 141 & 9.1 & 38.4 \\
\hline C & 1 & 125 & 60.2 & 3.5 & 28.3 \\
\hline $\mathbf{D}$ & 18 & 200 & 111 & 14.3 & 33.3 \\
\hline
\end{tabular}

a. Plasma samples were taken at $4-11 \mathrm{~h}$ after last administration.

b. All male; age, $27-42$ years; weight, $40-71.5 \mathrm{~kg}$.

life of $2.9 \mathrm{~h}$. The metabolites CSP and DCSP reached maximum values of 24.6 and $49.5 \mathrm{ng} \mathrm{ml}^{-1}$ at $1.0 \mathrm{~h}$ and were eliminated with half-lives of 3.4 and $1.9 \mathrm{~h}$, respectively. The values obtained with plasma from patients receiving oral administration of CCP dihydrochloride are summarized in Table 4. CCP, CSP and DCSP were detected in the patient plasma (dose range of CCP dihydrochloride, $50-200 \mathrm{mg} \mathrm{d}^{-1} /$ adult).

In conclusion, the proposed method is rapid and precise and sufficiently sensitive to measure plasma concentrations of $\mathrm{CCP}$ and its metabolites in the therapeutic dose range. This method should be useful for biomedical investigations of CCP.

The authors are grateful to Mr. Hiroyuki Moriyama of Tosoh Corporation for bovine serum albumin-coated cyanopropyl silica gel columns, and to Drs. Norifumi Kunimoto and Ikuya Ohta of Faculty of Medicine, Ryukyu University (Naha, Okinawa, Japan) for patient plasma samples.

\section{References}

1. J. Ishigooka, M. Murasaki, H. Wakatabe, S. Miura, K. Hikida, M. Shibata and H. Nobunaga, Psychopharmacology, 97, 303 (1989).

2. T. Sadanaga, K. Hikida, K. Tameto, M. Nakanishi, Y. Matsushima and Y. Ohkura, Jpn. J. Clin. Chem., 9, 351 (1980).

3. K. A. Ramsteiner, J. Chromatogr., 456, 3 (1988).

4. H. Imai, T. Masujima, I. Morita-Wada and G. Tamai, Anal. Sci., 389, 5 (1989).

5. K. Hikida, N. Ishii, Y. Inoue and Y. Ohkura, Bumseki Kagaku, 37, 566 ( 1988).

6. K. Hikida, Y. Inoue, T. Okuura, T. Miyazaki, N. Kojima and Y. Ohkura, Bunseki Kagaku, 38, 135 (1989).

7. K. Hikida, Y. Inoue, T. Miyazaki, N. Kojima and Y. Ohkura, J. Chromatogr., 495, 227 (1989).

8. K. Hikida, Y. Inoue, N. Kojima and Y. Ohkura, Jpn. J. Clin. Chem., 18, 180 (1989).

9. H. Yoshida, I. Morita, T. Masujima and H. Imai, Chem. Pharm. Bull., 30, 2287, (1982).

(Received February 15, 1990)

(Accepted March 12, 1990) 